\title{
dspace.vutbr.cz
}

\section{Experimental Verification of a Fractional-Order Wien Oscillator Built Using Solid-State Capacitors}

\author{
KARTCI, A.; AGAMBAYEV, A.; HASSAN, A. H.; BAGCI, H.; SALAMA, K. N.
}

Proceedings of the 2018 61st IEEE International Midwest Symposium on Circuits and Systems (MWSCAS), pp. 544-545

elSBN: 978-1-5386-7392-8

DOl: https://doi.org/10.1109/MWSCAS.2018.8624060

Accepted manuscript

(C2019 IEEE. Personal use of this material is permitted. Permission from IEEE must be obtained for all other uses, in any current or future media, including reprinting/republishing this material for advertising or promotional purposes, creating new collective works, for resale or redistribution to servers or lists, or reuse of any copyrighted component of this work in other works. KARTCl, A.; AGAMBAYEV, A.; HASSAN, A. H.; BAGCI, H.; SALAMA, K. N., " Experimental Verification of a Fractional-Order Wien Oscillator Built Using Solid-State Capacitors ", Proceedings of the 201861 st IEEE International Midwest Symposium on Circuits and Systems (MWSCAS), pp. 544-545, 2018. DOl: 10.1109/MWSCAS.2018.8624060. Final version is available at https://ieeexplore.ieee.org/document/8624060 


\title{
Experimental Verification of a Fractional-Order Wien Oscillator Built Using Solid-State Capacitors
}

\author{
Aslihan Kartci ${ }^{*}$, Agamyrat Agambayev ${ }^{\dagger}$, Ali H. Hassan ${ }^{\dagger \dagger}$, Hakan Bagci ${ }^{\dagger}$, and Khaled N. Salama ${ }^{\dagger}$ \\ *Faculty of Electrical Engineering and Communication, Brno University of Technology, Brno, Czech Republic \\ ${ }^{\dagger}$ Computer, Electrical and Mathematical Sciences and Engineering (CEMSE) Division \\ King Abdullah University of Science and Technology (KAUST), Thuwal, Saudi Arabia \\ ${ }^{\dagger}$ Electronics and Communications Engineering Department, Cairo University, Giza 12613, Egypt \\ Email: kartci@feec.vutbr.cz, agamyrat.agambayev@kaust.edu.sa, ali.h.hassan@ieee.org, hakan.bagci@kaust.edu.sa, \\ khaled.salama@kaust.edu.sa
}

\begin{abstract}
A new type of fractional-order capacitors (FOCs) is fabricated using a molybdenum disulfide $\left(\mathrm{MoS}_{2}\right)$-ferroelectric polymer composite. The phase angle of this FOC's impedance remains constant between $100 \mathrm{~Hz}$ and $10 \mathrm{MHz}$ with only a small deviation of \pm 4 degrees. The performance of the fabricated FOCs is further tested using the well-known Wien oscillator. The main motivation of this paper is to demonstrate the use of a broadband, and tunable FOC in a real world application.
\end{abstract}

Keywords-composite materials; constant phase element; fractional-order capacitor; Wien oscillator

\section{INTRODUCTION}

Impedance of a fractional-order capacitor (FOC) is expressed as $\mathrm{Z}(s)=s^{-\alpha}\left(C_{\alpha}\right)^{-1}$, where $\alpha$ is the fractional order $(0<\alpha<1), C_{\alpha}$ is the pseudo-capacitance (in units of $\left.\mathrm{F} \cdot \mathrm{s}^{\alpha-1}\right)$. Here, the (fractional-order) derivative with respect to time is represented with (complex number) $s^{-\alpha}$ in the Laplace domain. The fractional order $\alpha$, which is an additional degree of freedom, provides an excellent mechanism to describe memory and heredity properties of various materials and processes. Consequently, mathematical models making use of fractional derivatives can account for such effects more rigorously and accurately than their classical integer-order counterparts. The FOCs represent a way of implementing these mathematical models in electronic circuits. Recently, several approaches to fabricating FOCs have been proposed. For example, the FOCs listed in Table 1 are fabricated using polymer composites with different types of fillers. However, either their frequency range of operation (i.e., the frequency range where $\alpha$ remains constant) is not wide enough or they are not compatible for integration in electronic circuits.

TABLE I. COMPARISION OF DIFFERENT FOCS

\begin{tabular}{|l|l|c|c|}
\hline Refs & Composite Materials & Bandwidth & $\begin{array}{c}\text { Phase } \\
\text { Error }\end{array}$ \\
\hline$[1]$ & PMMA coating & $200 \mathrm{kHz}-1 \mathrm{MHz}$ & $\pm 2^{\circ}$ \\
\hline$[2]$ & rGO + polymer & $50 \mathrm{kHz}-2 \mathrm{MHz}$ & $\pm 3^{\circ}$ \\
\hline$[3]$ & IPMCs & $1 \mathrm{~Hz}-10 \mathrm{kHz}$ & Not given \\
\hline$[4,5]$ & Poly-based poly. com. & $100 \mathrm{kHz}-10 \mathrm{MHz}$ & $\pm 4^{\circ}$ \\
\hline$[6]$ & MWCNT + polymer & $150 \mathrm{kHz}-2 \mathrm{MHz}$ & $\pm 3^{\circ}$ \\
\hline $\begin{array}{l}\text { This } \\
\text { work }\end{array}$ & $\mathrm{MoS}_{2}+$ polymer & $100 \mathrm{~Hz}-10 \mathrm{MHz}$ & $\pm 4^{\circ}$ \\
\hline
\end{tabular}

The article is based on work from the COST Action CA15225, a network supported by COST (European Cooperation in Science and Technology). Research described in this paper was financed by King Abdullah University of Science and Technology and by the Czech Science Foundation under grant no. 16-11460Y.
In this work, printed circuit board (PCB)-compatible FOCs are fabricated using molybdenum disulfide $\left(\mathrm{MoS}_{2}\right)$ ferroelectric polymer composites. These FOCs' frequency range of operation is five decade wide between $100 \mathrm{~Hz}$ and $10 \mathrm{MHz}$. This is broadest constant phase zone that has been reported so far for an FOC. Furthermore, the real-life applicability of these FOCs is demonstrated by using them to design and fabricate a Wien oscillator.

\section{FABRICATION OF FOCS USING MOS 2 -POLYMER COMPOSITES}

\section{A. Fabrication Procedure}

The fabricated FOC is shown in Fig. 1(a). The bottom electrode is $200 \mathrm{~nm}$ Au sputtered on $\mathrm{SiO}_{2} / \mathrm{Si}$ substrate while the top electrode is sputtered on the dielectric composite with same thickness / material using a circular electrode with $3 \mathrm{~mm}$ diameter shadow mask where nine individual FOCs are fabricated on a $2 \mathrm{~cm} \times 2 \mathrm{~cm}$ sample area. The mixture of $0.03 \mathrm{~g} / \mathrm{ml} \mathrm{MoS}$ and $0.1 \mathrm{~g} / \mathrm{ml}$ polymer (PVDF-TrFe-CFE) in N, N-Dimethylformamide (DMF) solvent drop-casted onto the bottom electrode. The sample is flip-bonded on a PCB, so that each capacitor provides a separate connection for electrical measurements.

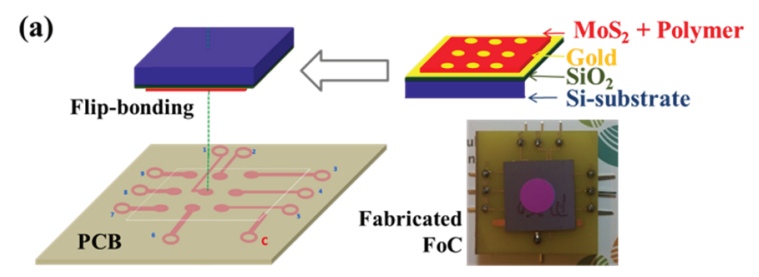

(b)

(c)
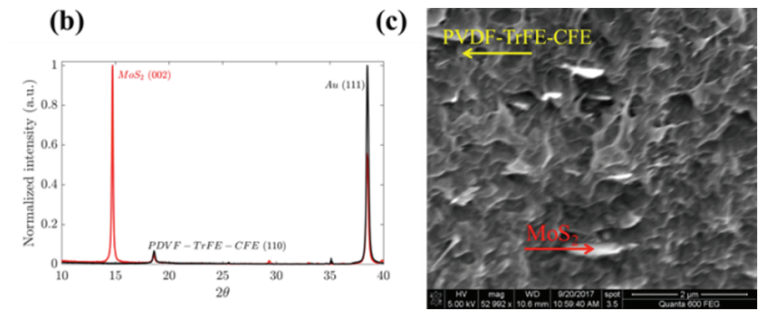

Fig. 1. (a) PCB compatible FOC fabricated using $\mathrm{MoS}_{2}$-polymer composite. (b) XRD spectra for PVDF-TrFE-CFE and $\mathrm{MoS}_{2} / \mathrm{PVDF}-\mathrm{TrFE}-\mathrm{CFE}$. (c) Its cross-sectional SEM image. 


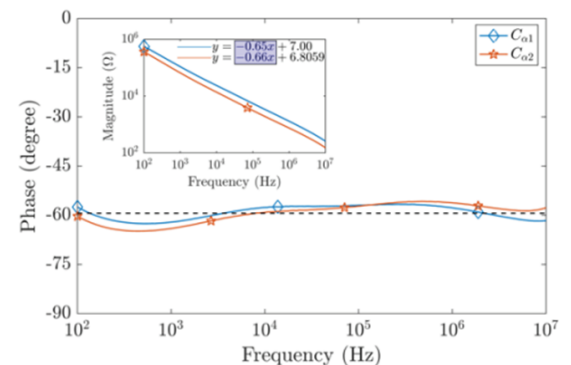

(a)

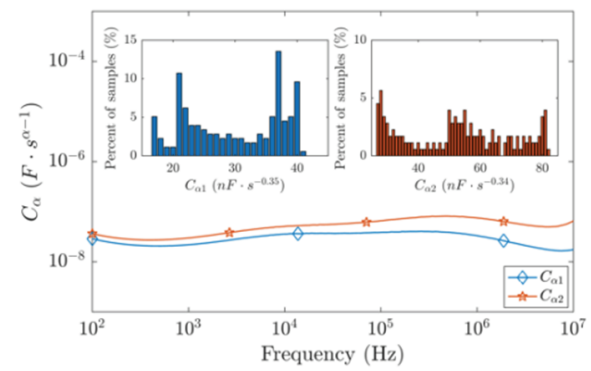

(b)

Fig. 2. (a) Phase and magnitude of the impedance and (b) pseudocapacitance of the fabricated FOCs.

\section{B. Imaging and Characterization of the FOCs}

$\mathrm{X}$-ray powder diffraction (XRD) patterns of the pristine polymer, PVDF-TrFE-CFE and $\mathrm{MoS}_{2}$ composite, are shown in Fig. 1(b). We observe intense peak at $14.77^{\circ}$ which belongs to $\mathrm{MoS}_{2}$. These results also show that no additional complex molecular structures are formed in the composite. Furthermore, the scanning electron microscopy (SEM) image provided in Fig. 1(c) shows that the $\mathrm{MoS}_{2}$ nanosheets are homogeneously distributed inside the composite. The impedance of two fabricated FOCs is analyzed using the Agilent 4994A Precision Impedance Analyzer with the $16048 \mathrm{G}$ model test fixture. Fig. 2(a) plots the phase of the impedance versus frequency and shows that it remains constant at $-58.5^{\circ}$ and $-59.4^{\circ}$ with only $\pm 4^{\circ}$ phase deviation between $100 \mathrm{~Hz}$ and $10 \mathrm{MHz}$ (five decades) for both of the FOCs. The pseudocapacitances of these FOCs, which are extracted from impedance magnitude measurements, are shown in Fig. 2(b). Their values at $25 \mathrm{kHz}$ are $C_{\alpha 1}=37.2 \mathrm{nF} \cdot \mathrm{s}^{-0.35}$ and $C_{\alpha 2}=55.2 \mathrm{nF} \cdot \mathrm{s}^{-0.34}$. It should be noted here the constant phase angle can be tuned by using different types of polymers in the composite.

\section{Fractional-Order WiEn OScillator}

The performance of the fabricated FOCs is demonstrated by using them to fabricate a fractional-order Wien oscillator (Fig. 3). In the circuit in Fig. $3, R_{1}=R_{2}=10 \mathrm{k} \Omega, R_{2}=47 \mathrm{k} \Omega$, $C_{\alpha 1}=37.2 \mathrm{nF} \cdot \mathrm{s}^{-0.35}$, and $C_{\alpha 2}=55.2 \mathrm{nF} \cdot \mathrm{s}^{-0.34}$. The measured frequency of oscillation (FO) is $24.87 \mathrm{kHz}$ while the one calculated using the above values is $23.52 \mathrm{kHz}$ [7]. The measurement is repeated after the FOCs are replaced with two conventional capacitors with a capacitance value of $30 \mathrm{nF}$ and $50 \mathrm{nF}$. For this case the FO is measured to be $0.414 \mathrm{kHz}$. This demonstrates that the fractional-order Wien oscillator has a significantly higher FO that its conventional counterpart. It should also be noted here that the peak-to-peak amplitudes of the output voltage of both oscillators are same and equal to $1.88 \mathrm{~V}$.

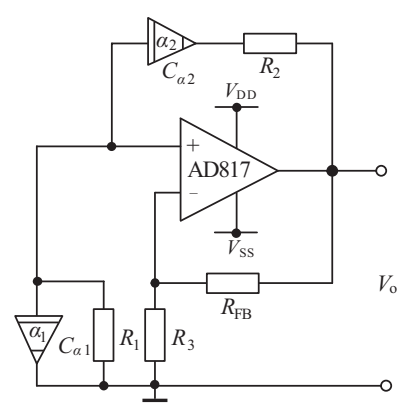

Fig. 3. Schematic of fractional-order Wien oscillator.



Fig. 4. Measured steady-state output voltage waveform of the fractionalorder Wien oscillator and the conventional one as an inset.

\section{CONCLUSION}

A tunable FOC with a frequency range of operation changing from $100 \mathrm{~Hz}$ to $10 \mathrm{MHz}$ (five decades) is introduced. The phase angle of the FOC's impedance varies within only $\pm 4^{\circ}$ in this frequency range. The performance of the FOCs is demonstrated by using them to design and fabricate a fractional-order Wien oscillator.

\section{REFERENCES}

[1] K. Biswas, S. Sen, and P. K. Dutta, "Realization of a constant phase element and its performance study in a differentiator circuit," IEEE Transactions on Circuits and Systems II: Express Briefs, vol. 53, pp. 802-806, 2006.

[2] A. M. Elshurafa, M. N. Almadhoun, K. N. Salama, and H. N. Alshareef, "Microscale electrostatic fractional capacitors using reduced graphene oxide percolated polymer composites," Applied Physics Letters, vol. 102, pp. 232901-232901-4.

[3] R. Caponetto, S. Graziani, F. L. Pappalardo, and F. Sapuppo, "Experimental characterization of ionic polymer metal composite as a novel fractional order element," Advances in Mathematical Physics, 2013.

[4] A. Agambayev, S. Patole, M. Farhat, A. Elwakil, H. Bagci, and K. N. Salama, "Ferroelectric fractional-order capacitors," ChemElectroChem, vol. 4, pp. 2807-2813, 2017.

[5] A. S. Elwakil, A. Agambayev, A. Allagui, and K. N. Salama, "Experimental demonstration of fractional-order oscillators of orders 2.6 and 2.7," Chaos, Solitons and Fractals, vol. 96, pp. 160-164, 2017.

[6] A. Agambayev, K. H. Rajab, A. H. Hassan, M. Farhat, H. Bagci, and K. N. Salama, "Towards fractional-order capacitors with broad tunable constant phase angles: Multi-walled carbon nanotube-polymer composite as a case study," Journal of Physics D: App. Physics, vol. 51, pp. 1-6, 2018.

[7] A. G. Radwan, A. S. Elwakil, and A. M. Soliman, "Fractional-order sinusoidal oscillators: Design procedure and practical examples," IEEE Trans. on Circuits and Systems I, vol. 55, pp. 2051-2063, 2008. 